\title{
Kinetic Performance of Aluminum and Iron Oxides in the Removal of Arsenate from Aqueous Environment
}

\author{
E. Bilgin Simsek and U. Beker
}

\begin{abstract}
Arsenate $(\mathrm{As}(\mathrm{V}))$ adsorption from aqueous solution onto clinoptilolite incorporating iron or aluminum oxides was investigated. The modified samples were characterized by nitrogen adsorption isotherms, TEM-EDX analysis. Kinetic models were applied to describe $\operatorname{As}(\mathbf{V})$ adsorption on each modified clinoptilolite samples. The kinetic data, explained best by the pseudo-second-order model by good regression coefficients.
\end{abstract}

Index Terms-Arsenic, adsorption kinetics, metal oxides.

\section{INTRODUCTION}

Arsenic presents in ground water in one of two oxidation states: arsenite $(\operatorname{As}(\mathrm{III}))$ and arsenate $(\operatorname{As}(\mathrm{V}))$. Arsenic is stable in several oxidation states, of which the arsenite, $\mathrm{As}(\mathrm{III})$, and arsenate, $\mathrm{As}(\mathrm{V})$, are the most common forms in natural waters. The dominant species of arsenic depend greatly on its surrounding environment. The $\mathrm{As}(\mathrm{V})$ is stable in oxidizing environment, whereas the As(III) is mainly found in reducing one [1]. Arsenic exposure is known to be associated with skin, lung, liver, kidney and prostate cancer (NRC 1999). There were regions including high arsenic concentrations such as Taiwan ( 34-558 $\mu \mathrm{g} / \mathrm{L}$ [2]; 10-1820 $\mu \mathrm{g} / \mathrm{L}[1])$ and Vietnam $(\sim 3050 \mu \mathrm{g} / \mathrm{L} \mathrm{b}$ in rural groundwater samples [3]).

The USEPA changed the maximum contaminant level for arsenic from $50 \mu \mathrm{g} / \mathrm{L}$ in 1974 to $10 \mu \mathrm{g} / \mathrm{L}$ in 2001 due to its long-term health effect [4].

Metallic oxides like iron, aluminum or manganese oxides have gained special attention in environmental remediation technologies in recent years. Especially widespread application of iron and aluminum oxides for water treatment has encouraged in evaluating them for arsenic adsorption. Toxicity of inorganic arsenic has caused various health effects [5], thus, different kinds of metal oxides were synthesized for estimating their arsenic removal efficiency. The challenge of these oxides, problems might occur owing to their fine particles [6]. An effective method to overcome these problems is to incorporate these oxides into/onto carriers of larger size such as zeolites.

The aim of this work is to carry out kinetic and isotherm studies on the adsorption of $\mathrm{As}(\mathrm{V})$ on iron or aluminum oxides modified clinoptilolite samples.

Manuscript received June 5, 2013; revised July 16, 2013.

E. Bilgin Simsek is with Yildiz Technical University (Istanbul) and Yalova University, Chemical and Process Engineering Department, Yalova, Turkey (e-mail: esrabilgin622@gmail.com).

U. Beker is with Yildiz Technical University, Chemical Engineering Department, Istanbul, Turkey (e-mail: ubeker@gmail.com).

\section{MATERIALS AND MethodS}

\section{A. Preparation of Adsorbents}

The previous study [7] concluded that the pretreated zeolites exhibited low or no adsorption capacities for $\mathrm{As}(\mathrm{V})$. However, major increases were observed for all metal oxide coated zeolites especially for bimetallic oxides coated ones. For that reason, further studies were carried out with iron or aluminum oxide doped ones.

Iron and aluminum oxides impregnated zeolites were prepared as described in previous study [7]: A defined amount of NC-Na was immersed in $200 \mathrm{ml}$ of metal solution and $\mathrm{pH}$ of the solution was raised to 7.0 by addition of $\mathrm{NaOH}$. The stirring was continued for $1 \mathrm{~h}$ and then the suspension was filtered and washed with deionized water in column and dried at $338 \mathrm{~K}$. The iron oxide immobilized NC-Na was prepared with $\mathrm{FeCl}_{2}$ solution and sample was designated as NC-Fe. Similarly, aluminum oxide immobilized NC-Na was synthesized by using $\mathrm{AlCl}_{3}$ solution and sample was coded as NC-Al.

\section{B. Characterization Studies}

The nitrogen adsorption experiments were conducted with Quantachrome Autosorb instrument. The specific surface area $\left(\mathrm{S}_{\mathrm{BET}}\right)$, micropore volume and pore size distribution of samples were calculated using BET (Brunauer, Emmett, Teller), t-plot and BJH (Barett-Joyner-Halenda) methods, respectively. Transmission electron microscopy (TEM) observations and elemental analysis of samples were performed with a high resolution electron microscope (FEI Tecnai G2 F20 X-Twin) operated at $200 \mathrm{kV}$ with an Energy Dispersive X-ray spectroscopy system attachment (TEM-EDX).

\section{Adsorption Experiments}

$\mathrm{As}(\mathrm{V})$ adsorption kinetic studies were carried out by adding defined amount of modified samples into $500 \mathrm{~mL}$ of $\mathrm{As}(\mathrm{V})$ solutions at different temperatures $\left(25,45\right.$ and $\left.65^{\circ} \mathrm{C}\right)$. The arsenic concentration was detected at $193.7 \mathrm{~nm}$ using an atomic absorption spectrometer (Analytik Jena ContrAA 700 TR).

Arsenate sorption capacity was calculated by using the following equation (Eq. (1)):

$$
q_{e}=\frac{\left(C_{0}-C_{e}\right) \times V}{m}
$$

where $q_{e}$ is the arsenate adsorption capacity $(\mathrm{mg} / \mathrm{g}), C_{0}$ is the initial concentration of arsenate $(\mathrm{mg} / \mathrm{L}), C_{e}$ is the equilibrium $\mathrm{As}(\mathrm{V})$ concentration $(\mathrm{mg} / \mathrm{L}), V$ is the solution volume $(\mathrm{L})$ and $m$ is the adsorbent dosage (g). 
The experimental data was applied by the pseudo-first- and pseudo-second order kinetic models.

\section{RESUlTS AND DISCUSSION}

\section{A. Characterization Results}

The textural properties of samples from the nitrogen adsorption isotherm are summarized in Table I. The total pore volume values of $\mathrm{NC}-\mathrm{Fe}$ and $\mathrm{NC}-\mathrm{Al}$ samples were found 0.221 and $0.173 \mathrm{~cm}^{3} / \mathrm{g}$, respectively.

TABLE I: TEXTURAL PROPERTIES OF SAMPLES

\begin{tabular}{|l|l|l|}
\hline Sample & NC-Fe & NC-Al \\
\hline $\mathrm{S}_{\text {BET }}\left(\mathrm{m}^{2} / \mathrm{g}\right)$ & 69.62 & 22.20 \\
\hline $\mathrm{V}_{\mathrm{a}}\left(\mathrm{cm}^{3} / \mathrm{g}\right)$ & 0.221 & 0.173 \\
\hline
\end{tabular}

$\mathrm{S}_{\mathrm{BET}}$ : Specific surface area, $\mathrm{V}_{\mathrm{a}}$ : Total pore volume

The increases in total pore volume of modified samples are probably due to the higher content of iron or aluminum in the composite. This could be explained by the formation of secondary pore structure during the precipitation of the metal oxide particles [8]. But the formation of small pores had no significant effect to the total pore volume due to the zero values of micropore volume for modified zeolites.
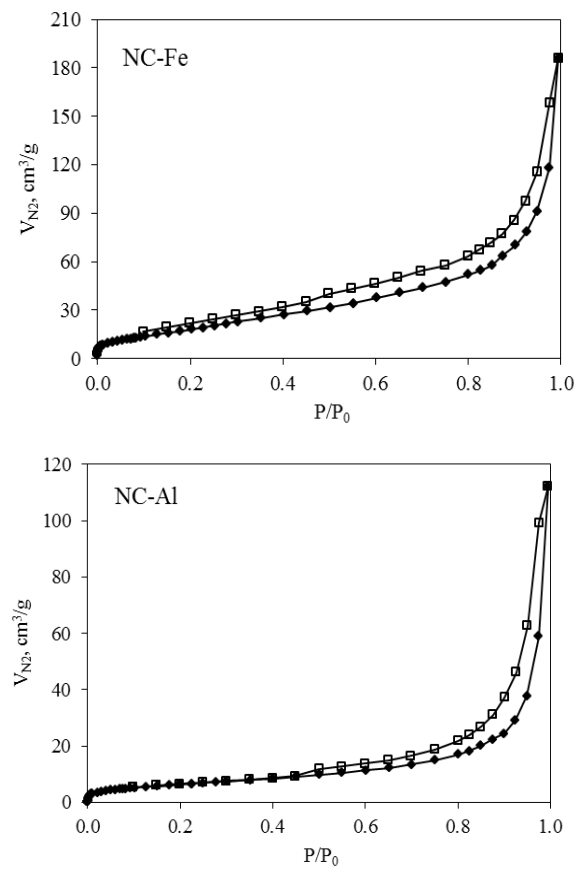

Fig. 1. Nitrogen adsorption-desorption isotherms ( $\bullet$ : adsorption : desorption)

Nitrogen adsorption and desorption isotherms of all samples (Fig. 1) were fitted to Type-V with a B- or H3-type of hysteresis loop in accordance with the IUPAC classification [9]. The isotherms showing hysteresis loops depict characteristic feature of mesopores [10].

The TEM image of NC-Fe (Fig. 2) was confirmed by the morphology of the crystals which form thin plates could be identified as $\delta$ - $\mathrm{FeOOH}$ (feroxyhyte) or $\alpha-\mathrm{FeO}(\mathrm{OH})$ (goethite) forms [11]. TEM-EDX analysis shows that approximately $47.1 \mathrm{wt} \% \mathrm{Fe}$ ions were aggregated at the surface of zeolite support.

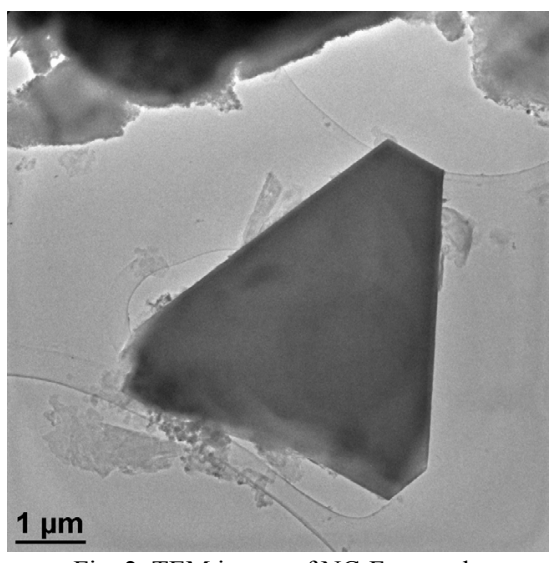

Fig. 2. TEM image of NC-Fe sample

\section{B. Kinetic Models}

Adsorption kinetic plays an important role on the physical and/or chemical characteristics of the sorbent material, which also influenced the sorption mechanism [12]. Although many models like homogeneous diffusion model or the pore diffusion model have been proposed to interpret the transport of solutes inside adsorbents, the mathematical complexity of these models makes them inconvenient for practical use. From a viewpoint of system design, lumped analysis of the adsorption rates is thus considered to be sufficient for practical operation [13].

The experimental results showed that NC-Fe and NC-Al samples removed $74 \%$ and $65 \%$ of $\mathrm{As}(\mathrm{V})$ at the end of 8 hour. For NC-Fe sample, maximum As(V) adsorption capacity was obtained as $2.716 \mathrm{mg} / \mathrm{g}$ while that of $\mathrm{NC}-\mathrm{Al}$ was found as $1.338 \mathrm{mg} / \mathrm{g}$ at equilibrium (Fig. 3).

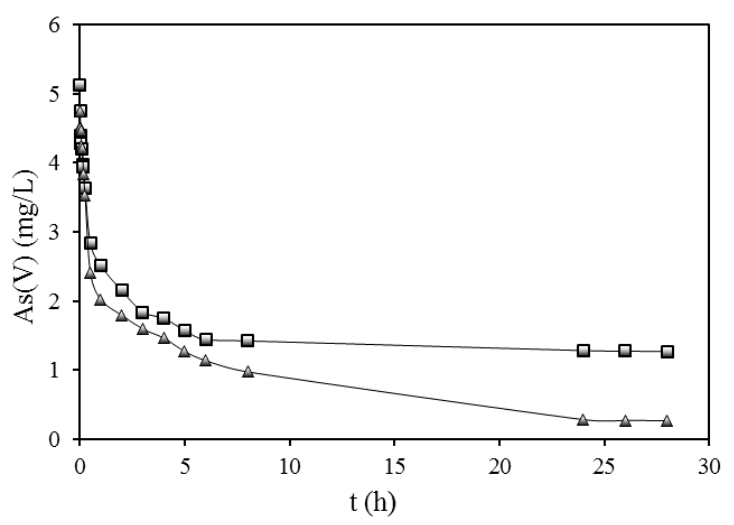

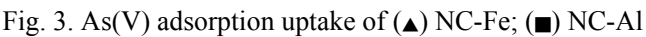

The prediction of adsorption rate provides important information for designing batch adsorption systems. Information on the kinetics of pollutant uptake is needed for selecting optimum operating conditions for full-scale batch process. In the present work, general kinetic equations were applied to the experimental data. The pseudo-first-order rate expression of Lagergren is generally described by the following equation [14]:

$$
\frac{d q_{t}}{d t}=k_{1} \cdot\left(q_{e}-q_{t}\right)
$$

where $q_{e}$ and $q_{t}$ are the amounts of $\mathrm{As}(\mathrm{V})$ adsorbed on the adsorbents at equilibrium and at time, $t$ ( $\mathrm{min})$, respectively and $k_{l}$ is the rate constant $(1 / \mathrm{min})$. Integrating and applying 
the boundary conditions, $t=t$ and $q_{t}=q_{e}$ takes the form:

$$
\log \left(q_{e}-q_{t}\right)=\log \left(q_{e}\right)-\left(\frac{k_{1}}{2.303}\right) . t
$$

The other main kinetic model was described as pseudo-second-order process [15] by the following equation:

$$
\frac{d q_{t}}{d t}=k_{2} \cdot\left(q_{e}-q_{t}\right)^{2}
$$

where, $q_{e}$ and $q_{t}$ have the same meaning as mentioned previously, and $k_{2}$ is the rate constant for the pseudo second-order kinetics. Rearranging this equation to a linear form:

$$
\frac{t}{q_{t}}=\frac{1}{k_{2} \cdot q_{e}^{2}}+\frac{1}{q_{e}} t
$$

The plots of $t / q_{t}$ versus $t$ are shown in Fig. 4 for $\mathrm{NC}-\mathrm{Fe}$ and $\mathrm{NC}-\mathrm{Al}$. The theoretical $\mathrm{q}_{\mathrm{t}}$ values estimated from the first-order kinetic model gave significantly different values compared to experimental values, and the correlation coefficients were also found to be lower. These results showed that the first-order kinetic model did not well describe As(V) sorption system.

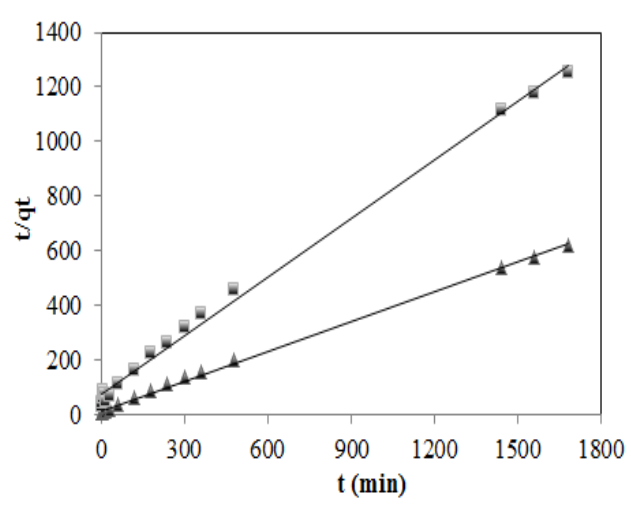

\begin{tabular}{|c|c|c|c|}
\hline Temperature & $298 \mathrm{~K}$ & $318 \mathrm{~K}$ & $338 \mathrm{~K}$ \\
\hline \multicolumn{4}{|l|}{$\mathrm{NC}-\mathrm{Fe}$} \\
\hline $\mathrm{q}_{\mathrm{e}}(\mathrm{mg} / \mathrm{g})$ & 2.716 & 2.839 & 3.183 \\
\hline \multicolumn{4}{|c|}{ Pseudo-first-order } \\
\hline$q_{t}(m g / g)$ & 1.742 & 1.533 & 1.083 \\
\hline$k_{1}(1 / \mathrm{min})$ & 0.007 & 0.006 & 0.002 \\
\hline$R^{2}$ & 0.930 & 0.967 & 0.565 \\
\hline \multicolumn{4}{|c|}{ Pseudo-second-order } \\
\hline$q_{t}(m g / g)$ & 2.728 & 2.835 & 2.960 \\
\hline$k_{2}(\mathrm{~g} / \mathrm{mg} \min )$ & 0.009 & 0.011 & 0.032 \\
\hline$R^{2}$ & 0.998 & 0.997 & 0.997 \\
\hline \multicolumn{4}{|l|}{$N C-A l$} \\
\hline $\mathrm{q}_{\mathrm{e}}(\mathrm{mg} / \mathrm{g})$ & 1.338 & 1.401 & 1.473 \\
\hline \multicolumn{4}{|c|}{ Pseudo-first-order } \\
\hline$q_{t}(\mathrm{mg} / \mathrm{g})$ & 1.076 & 1.051 & 1.058 \\
\hline$k_{1}(1 / \mathrm{min})$ & 0.006 & 0.005 & 0.007 \\
\hline$R^{2}$ & 0.959 & 0.966 & 0.932 \\
\hline \multicolumn{4}{|c|}{ Pseudo-second-order } \\
\hline$q_{t}(m g / g)$ & 1.395 & 1.393 & 1.494 \\
\hline$k_{2}(g / m g . k)$ & 0.006 & 0.009 & 0.011 \\
\hline$R^{2}$ & 0.991 & 0.993 & 0.996 \\
\hline
\end{tabular}

Fig. 4. Pseudo-second-order kinetic model of ( $\mathbf{\Delta}) \mathrm{NC}-\mathrm{Fe} ;(\boldsymbol{\square}) \mathrm{NC}-\mathrm{Al}$

TABLE II: KINETIC PARAMETERS
However, the theoretical $q_{t}$ values for the both sorbents were very close to the experimental $q_{e}$ values in the case of second-order kinetics (Table II). Based on the values of linear regression coefficients $\left(\mathrm{R}^{2}\right)$ of each applied kinetic model, it could be suggested that $\mathrm{As}(\mathrm{V})$ adsorption kinetics for both sorbents described the pseudo-second order equation $\left(\mathrm{R}_{\mathrm{NC}-\mathrm{Na}}{ }^{2}=0.9982 ; \mathrm{R}_{\mathrm{NC}-\mathrm{Al}}{ }^{2}=0.9964\right)$.

The pseudo-second-order model is based on the assumption that the rate-determining step may be a chemical sorption involving valence forces through sharing or exchange of electrons between adsorbent and sorbate [16].

The presence of aluminum and iron in zeolite enhanced the $\mathrm{As}(\mathrm{V})$ uptake significantly. NC-Fe sample was found more effective adsorbent than $\mathrm{NC}-\mathrm{Al}$ sample as observed by others [17]-[19].

\section{CONCLUSION}

The results indicated that iron oxide incorporated clinoptilolite was better adsorbent for $\mathrm{As}(\mathrm{V})$ removal than the aluminum one suggesting the $\mathrm{As}(\mathrm{V})$ adsorption depends on the metallic species in the zeolite surface.

This study provides an insight into arsenic adsorption onto metal oxides supported onto natural, cheap and eco-friendly material.

\section{REFERENCES}

[1] B. K. Mandal and K.T. Suzuki, "Arsenic round the world: a review," Talanta, vol. 58, pp. 201-235, August 2002.

[2] C. W. Liu, K. H. Lin, and Y. M. Kuo, "Application of factor analysis in the assessment of groundwater quality in a blackfoot disease area in Taiwan," Science of Total Environment, vol. 313, pp. 77-89, 2003.

[3] M. Berg, H. C. Tran, T. C. Nguyen, H. V. Pham, R. Schertenleib, and W. Giger, "Arsenic contamination of groundwater and drinking water in Vietnam: a human health threat," Environmental Science and Technology, vol. 35 pp. 2621-2626, 2001.

[4] N. Melitas, J. Wang, M. Conklin, P. O’Day, and J. Farrell, "Understanding soluble arsenate removal kinetics by zero-valent iron media," Environmental Science and Technology, vol. 36, pp. 2074-2081, 2002.

[5] M. F. Hughes, D. J. Thomas, and E. M. Kenyon, "Toxicology and Epidemiology of Arsenic and Its Compounds," in Arsenic Environmental Chemistry, Health Threats and Waste Treatment, K. R. Henke, Wiley, New York, 2009, pp. 237-277.

[6] M. Hua, S. Zhang, B. Pan, W. Zhang, L. Lv, and Q. Zhang, "Heavy metal removal from water/wastewater by nanosized metal oxides: A review," Journal of Hazardous Materials, vol. 211- 212, pp. 317- 331, April 2012.

[7] E. Bilgin Simsek, E. Ozdemir, U. Beker, "Zeolite supported mono- and bimetallic oxides: Promising adsorbents for removal of $\mathrm{As}(\mathrm{V})$ in aqueous solutions," Chemical Engineering Journal, vol. 220, pp. 402-411, March 2013.

[8] Z. Orolínová and A. Mockovciaková, "Structural study of bentonite/iron oxide composites," Mater. Chem. Phys., vol. 114 pp. 956-961, April 2009.

[9] F. Rouquerol, J. Rouquerol, and K. Sing, Adsorption by Powder \& Porous Solids, Academic Press, San Dieogo, USA, 1999.

[10] M. D. Donohue and G. L. Aranovich, "Adsorption hysteresis in porous solids,” J. Colloid Interface Sci., vol. 205, pp. 121-130, May 1998.

[11] R. M. Cornell and U. Schwertmann, The iron oxides: structure, properties, reactions, occurence and uses, Wiley, Germany, 2003.

[12] D. Ranjan, M. Talat, and S. H. Hasan, "Biosorption of arsenic from aqueous solution using agricultural residue 'rice polish'," Journal of Hazardous Materials, vol. 166, pp. 1050-1059, July 2009.

[13] M. Bilici Baskan and A. Pala, "Removal of arsenic from drinking water using modified natural zeolite," Desalination, vol. 281, pp. 396-403, October 2011.

[14] Y. S. Ho, "Citation review of Lagergren kinetic rate equation on adsorption reactions," Scientometrics, vol. 59, pp. 171-177, 2004. 
[15] Y. S. Ho and G. McKay, "Pseudo-second order model for sorption processes," Process Biochemistry, vol. 34, pp. 451-465, 1999.

[16] Y. S. Ho, "Second-order kinetic model for the sorption of cadmium onto tree fern: a comparison of linear and non-linear methods," Water Research, vol. 40, pp. 119-125, January 2006.

[17] M. Pigna, G. S. R. Krishnamurti, and A. Violante, "Kinetics of arsenate sorption-desorption from metal oxides: Effect of Residence Time," Soil Sci. Soc. Am. J., vol. 70, pp. 2017-2027, November 2006.

[18] J. Youngran, M. Fan, J. Van Leeuwen, and J. F. Belczyk, "Effect of competing solutes on arsenic(V) adsorption using iron and aluminum oxides," J. Environ. Sci., vol. 19, pp. 910-919, March 2007.

[19] A. Jain, V. K. Sharma, and O. S. Mbuya, "Removal of arsenite by $\mathrm{Fe}(\mathrm{VI}), \mathrm{Fe}(\mathrm{VI}) / \mathrm{Fe}(\mathrm{III})$, and $\mathrm{Fe}(\mathrm{VI}) / \mathrm{Al}(\mathrm{III})$ salts: Effect of $\mathrm{pH}$ and anions," Journal of Hazardous Materials, vol. 169, pp. 339-344, 2009.

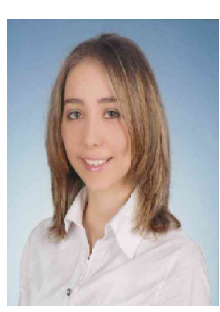

Esra Bilgin Simsek was born in 1987 in Istanbul, Turkey. She obtained her bachelor degree in the field of chemical engineering from Yildiz Technical University (2008). She finished her master in 2010 in Yildiz Technical University and she currently pursuing her $\mathrm{PhD}$ at the same university with the interest in the wastewater treatment.

She has been working as a Research Assistant in the Chemical and Process Engineering Department at
Yalova University, Turkey, since 2010. She currently works at Yildiz Technical University. She has published five papers in international refereed journals. Her research interests are adsorption and ion exchange; sorbent preparation; magnetic nanoparticles for wastewater treatment; reaction kinetics; advanced separation processes.

Ms. Bilgin Simsek is a member of Chamber of Chemical Engineers.

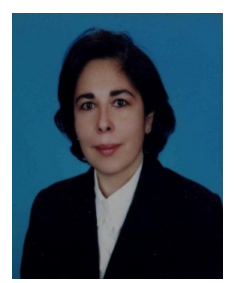

Ulker Beker was born in 1960. In 1982, she graduated from Istanbul Technical University of Chemical Engineering Department. She finished her master in 1986 and completed $\mathrm{PhD}$ in1992 in Chemical Engineering Department in Istanbul Technical University.

She worked in Istanbul Technical University of Chemical Engineering Department between 1984 and 2001. Continuing from 2001, and current to date, she is working as lecturer and Professor in Y1ldız Technical University of Chemical Engineering Department. She has published many papers in international refereed journals and delivered several invited lectures at national and international conferences. Her research interests are wastewater treatment; adsorption and ion exchange; sorbent preparation; magnetic nanoparticles for wastewater treatment; reaction kinetics; advanced separation processes.

Prof. Beker is a member of Chamber of Chemical Engineers. 